\title{
Evaluation of PMI-5011, an ethanolic extract of Artemisia dracunculus L., on peripheral neuropathy in streptozotocin-diabetic mice
}

\author{
PIERRE WATCHO $^{1,2}$, ROMAN STAVNIICHUK ${ }^{1}$, PIERRE TANE ${ }^{2}$, HANNA SHEVALYE ${ }^{1}$, \\ YURY MAKSIMCHYK ${ }^{1}$, PAL PACHER ${ }^{3}$ and IRINA G. OBROSOVA ${ }^{1}$ \\ ${ }^{1}$ Pennington Biomedical Research Center, Louisiana State University System, Baton Rouge, LA, USA; \\ ${ }^{2}$ Department of Chemistry, University of Dschang, Dschang, Cameroon; ${ }^{3}$ Section on Oxidative \\ Stress Tissue Injury, Laboratory of Physiological Studies, NIH/NIAAA, Bethesda, MD, USA
}

Received November 16, 2010; Accepted December 13, 2010

DOI: 10.3892/ijmm.2011.597

\begin{abstract}
We previously reported that PMI-5011, an ethanolic extract of Artemisia dracunculus L., alleviates peripheral neuropathy in high fat diet-fed mice, a model of prediabetes and obesity developing oxidative stress and pro-inflammatory changes in the peripheral nervous system. This study evaluated PMI-5011 on established functional, structural, and biochemical changes associated with Type I diabetic peripheral neuropathy. C57B16/J mice with streptozotocin-induced diabetes of a 12-week duration, developed motor and sensory nerve conduction velocity deficits, thermal and mechanical hypoalgesia, tactile allodynia, and intra-epidermal nerve fiber loss. PMI-5011 (500 mg/kg/day for 7 weeks) alleviated diabetes-induced nerve conduction slowing, small sensory nerve fiber dysfunction, and increased intra-epidermal nerve fiber density. PMI-5011 blunted sciatic nerve and spinal cord 12/15-lipoxygenase activation and oxidative-nitrosative stress, without ameliorating hyperglycemia or reducing sciatic nerve sorbitol pathway intermediate accumulation. In conclusion, PMI-5011, a safe and non-toxic botanical extract, may find use in the treatment of diabetic peripheral neuropathy.
\end{abstract}

\section{Introduction}

Diabetic peripheral neuropathy (DPN) affects approximately $50 \%$ of patients with diabetes mellitus, and is a leading cause of foot amputation $(1,2)$. Clinical manifestations of advanced DPN include motor (MNCV) and sensory (SNCV) nerve conduction velocity deficits and increased vibration and thermal perception thresholds culminating in sensory loss

Correspondence to: Dr Irina G. Obrosova, Pennington Biomedical Research Center, Louisiana State University, 6400 Perkins Road, Baton Rouge, LA 70808, USA

E-mail: obrosoig@pbrc.edu

Key words: diabetic neuropathy, PMI-5011, oxidative-nitrosative stress which develops at least partially because of degeneration of all types of nerve fibers in the somatic nerve. A significant proportion of patients with DPN suffers from abnormal sensations such as paresthesias, allodynia, hyperalgesia, and from spontaneous pain (2-4). Except for the aldose reductase inhibitor, epalrestat, in Japan (5) and of $\alpha$-lipoic acid in several countries (6), no pathogenetic treatment for DPN is currently available. A number of pharmacological agents that looked promising in animal studies, have been withdrawn from clinical trials because of adverse side-effects $(2,4)$. Therefore, identification of safe therapeutic approaches for DPN is important.

PMI-5011, an ethanolic extract of Artemisia dracunculus L. $(7,8)$ with a good safety profile $(7)$, contains, at least, six bioactive compounds including the polyphenols, 6-demethoxycapillarisin and 2',4'-dihydroxy-4-methoxydihydrochalcone (9). PMI-5011 has been reported to improve insulin and insulin receptor signaling $(10,11)$, and to inhibit aldose reductase (12), oxidative stress (13), and nuclear factor- $\kappa \mathrm{B}(\mathrm{NF}-\kappa \mathrm{B})$-regulated inflammatory mechanisms (14). Taking into consideration that impaired insulin signaling (15), increased sorbitol pathway activity (16-20), oxidative-nitrosative stress (21-25), and NF- $\kappa$ B-mediated pro-inflammatory response (26-29) have been identified as important factors in the pathogenesis of DPN, there is a strong rationale for evaluating PMI-5011 on the structural and functional manifestations of this devastating complication of diabetes. We recently reported a beneficial effect of PMI-5011 on MNCV and SNCV deficits and small sensory nerve fiber dysfunction characteristic of a high fat diet (HFD)induced neuropathy of prediabetes and alimentary obesity (13). The purpose of this study was to evaluate PMI-5011 on established functional, structural, and biochemical changes of DPN in streptozotocin (STZ)-diabetic mice, a model of Type I diabetes.

\section{Materials and methods}

Reagents. All chemicals were of reagent-grade quality unless otherwise stated, and were purchased from Sigma Chemical Co. (St. Louis, MO). PMI-5011, an ethanolic extract of Artemisia dracunculus L., was prepared and analyzed as 
previously described (8). Ethanol was completely removed after extraction by heating in a rotavapor. The mouse monoclonal (clone 1A6) anti-nitrotyrosine (NT) antibody for Western blot analysis of nitrated proteins was purchased from Millipore (Billerica, MA, USA). The rabbit polyclonal (clone H-100) anti-12-lipoxygenase antibody was obtained from Santa Cruz Biotechnology (Santa Cruz, CA, USA). For assessment of intra-epidermal nerve fiber density (INFD), rabbit polyclonal anti-protein gene product 9.5 (PGP 9.5) antiserum was obtained from UltraClone (Isle of Wight, UK); Alexa Fluor 488 goat anti-rabbit highly cross-adsorbed $\operatorname{IgG}(\mathrm{H}+\mathrm{L})$ was from Invitrogen (Eugene, OR, USA); SuperBlock blocking buffer from Thermo Scientific (Rockford, IL, USA); and the optimum cutting temperature (O.C.T.) compound from Sakura Finetek USA (Torrance, CA, USA). VectaShield Mounting Medium was obtained from Vector Laboratories (Burlingame, CA, USA). Other reagents for immunohistochemistry were purchased from Dako Laboratories, Inc. (Santa Barbara, CA, USA).

Animals. The experiments were performed in accordance with regulations specified by The Guide for the Care and Handling of Laboratory Animals (NIH Publication No. 85-23) and Pennington Biomedical Research Center Protocol for Animal Studies. Mature C57B16/J mice were purchased from Jackson Laboratories. All the mice were fed standard mouse chow (PMI Nutrition International, Brentwood, MO, USA) and had access to water ad libitum. Diabetes was induced by streptozotocin (STZ) as previously described (30). Blood samples for glucose measurements were taken from the tail vein three days after STZ injection and the day before the animals were sacrificed. The mice with blood glucose $>13.8 \mathrm{mM}$ were considered diabetic. Non-diabetic and diabetic mice were divided into two groups with similar body weights and blood glucose concentrations that were maintained with or without treatment with PMI-5011 $(500 \mathrm{mg} / \mathrm{kg} /$ day, for 7 weeks after 12 weeks without treatment). Physiological and behavioral measurements were taken at three time-points i.e., at the beginning of the study and before and after PMI-5011 treatment. The tests were done in the following order: tactile responses to flexible von Frey filaments (first day), thermal algesia by tail-flick test (second day), thermal algesia by paw withdrawal test (third day), mechanical algesia by tail-pressure Randall-Selitto test (fourth day), and MNCV and SNCV (fifth day). MNCV and SNCV were measured in mice anesthetized with a mixture of ketamine and xylazine ( $45 \mathrm{mg} / \mathrm{kg}$ body weight and $15 \mathrm{mg} / \mathrm{kg}$ body weight, respectively, i.p.).

Anesthesia, euthanasia and tissue sampling. Animals were sedated by $\mathrm{CO}_{2}$, and immediately sacrificed by cervical dislocation. Sciatic nerves and spinal cords were rapidly dissected and frozen in liquid nitrogen for subsequent assessment of 12/15-lipoxygenase (12/15-LO) and nitrated protein expression, and 12(S)hydroxyeicosatetraenoic acid [12(S)HETE], glucose, sorbitol, and fructose concentrations. Footpads were sampled for assessment of INFD.

Physiological tests. Sciatic MNCV and hind-limb digital SNCV were measured as described elsewhere (30). The TCAT-2 temperature controller with a RET-3 temperature probe and an
HL-1, heat lamp (Physitemp Instruments, Inc., Clifton, NJ) were used to maintain body and hind-limb temperature at $37^{\circ} \mathrm{C}$.

Behavioral tests. Thermal algesia was assessed by plantar (Hargreaves) and tail-flick tests, tactile response thresholds by the flexible von Frey filament test, and the mechanical withdrawal thresholds by the tail-pressure Randall-Selitto test as previously described in detail $(31,32)$.

Intra-epidermal nerve fiber density. Footpads were fixed in ice-cold Zamboni's fixative for $3 \mathrm{~h}$, washed in $100 \mathrm{mM}$ phosphate-buffered saline (PBS) overnight, and then in PBS containing increasing concentrations of sucrose i.e., 10, 15, and $20 \%$, for $3 \mathrm{~h}$ in each solution. After washing, the samples were snap-frozen in O.C.T. compound and stored at $-80^{\circ} \mathrm{C}$. Three longitudinal $50 \mu \mathrm{m}$-thick footpad sections from each mouse were cut on a Leica CM1950 cryostat (Leica Microsystems, Nussloch, Germany). Non-specific binding was blocked by $3 \%$ goat serum containing $0.5 \%$ porcine gelatin and $0.5 \%$ Triton X-100 in SuperBlock blocking buffer at room temperature, for $2 \mathrm{~h}$. The sections were incubated overnight with PGP 9.5 antiserum (1:400 dilution), at $4^{\circ} \mathrm{C}$, after which the secondary Alexa Fluor $488 \operatorname{IgG}(\mathrm{H}+\mathrm{L})$ in 1:1000 was applied at room temperature, for $1 \mathrm{~h}$. Sections were then coverslipped with VectaShield mounting medium. Intra-epidermal nerve fiber profiles were counted blindly by three independent investigators under the Axioplan 2 microscope (Zeiss) at 40x magnification, and the average values were used. The length of the epidermis was assessed on the microphotographs of stained sections taken at 5x magnification with a $3 i$ Everest imaging system (Intelligent Imaging Innovations, Inc., Denver, CO, USA) equipped with an Axioplan 2 microscope (Zeiss), using NIH ImageJ software (version 1.42q). An average of $2.8 \pm 0.3 \mathrm{~mm}$ of the sample length was investigated to calculate the number of nerve fiber profiles per $\mathrm{mm}$ of the epidermis. Representative images of intra-epidermal nerve fibers were obtained by confocal laser scanning microscopy at $40 \mathrm{x}$ magnification, using the Leica TCS SP5 confocal system (Leica Microsystems, Mannheim, Germany).

Biochemical studies. All biochemical measurements were performed in the sciatic nerve and spinal cord as previously described $(33,34)$. 12/15-LO and nitrated protein expression was assessed by Western blot analysis; 12(S)HETE concentration by ELISA, and glucose, sorbitol, and fructose concentrations by enzymatic spectrofluorometric methods with hexokinase/glucose 6-phosphate dehydrogenase, sorbitol dehydrogenase, and fructose dehydrogenase, respectively. Fluorescence measurements were taken with the LS55 Luminescence Spectrometer (Perkin-Elmer, MA).

Statistical analysis. The results are expressed as mean \pm SEM. Data were subjected to the equality of variance F-test, and then to $\log$ transformation, if necessary, before one-way analysis of variance. Where overall significance $(\mathrm{P}<0.05)$ was attained, between group comparisons for multiple groups were conducted using the Student Newman-Keuls multiple-range test. When between-group variance differences could not be normalized by log transformation (data sets for body weights and plasma glucose), the data were analyzed by the non-parametric 
Kruskal-Wallis one-way analysis of variance, followed by the Bonferroni-Dunn test for multiple comparisons. Individual pairwise comparisons between control and STZ-diabetic mice (12-week time point) and between the corresponding groups before (12-week time point) and after (19-week time point) PMI-5011 treatment were performed using the unpaired or paired two-tailed Student's t-test or Mann-Whitney rank sum test where appropriate. Significance was defined at $\mathrm{P}<0.05$.

\section{Results}

The initial (prior to STZ administration) body weights were similar in all the experimental groups (Table I). Weight gain at the end of the 12-week period after STZ administration was similarly (by 22 and 21\%) reduced in both diabetic groups compared to non-diabetic controls. PMI-5011 treatment for 7 weeks did not affect weight gain in either control or diabetic mice. Initial (after STZ administration) non-fasting blood glucose concentrations were $\sim 2$-fold higher in diabetic mice compared with the non-diabetic control group. Hyperglycemia progressed with the prolongation of diabetes, and there was an $\sim 3$-fold difference in the intermediate (12-week time point) and final (19-week time point) blood glucose concentrations between diabetic and non-diabetic mice. PMI-5011 treatment did not affect non-fasting blood glucose concentrations in either non-diabetic or diabetic mice.

Diabetic mice displayed 20\% MNCV and SNCV deficits at the 12-week time point i.e., prior to PMI-5011 intervention (Table II). Both MNCV and SNCV were similar in non-diabetic mice at the beginning of the study and at the 12-week time point which indicates that diabetes-induced nerve conduction slowing did not develop due to alterations in peripheral nerve growth and maturation. Untreated diabetic mice with a 19-week duration of STZ-diabetes displayed 15 and $19 \%$ deficits in MNCV and SNCV, respectively, compared with the corresponding non-diabetic controls. PMI-5011

Table I. Body weights and blood glucose concentrations in non-diabetic and diabetic mice maintained with or without PMI-5011 treatment.

\begin{tabular}{|c|c|c|c|c|}
\hline Variables & Control & $\begin{array}{l}\text { Control with } \\
\text { PMI-5011 }\end{array}$ & Diabetic & $\begin{array}{c}\text { Diabetic with } \\
\text { PMI-5011 }\end{array}$ \\
\hline \multicolumn{5}{|c|}{ Baseline (after induction of STZ-diabetes) } \\
\hline Body weight (g) & $24.5 \pm 0.5$ & & $24.1 \pm 0.6$ & \\
\hline Blood glucose (mmol/l) & $8.5 \pm 0.3$ & & $17.1 \pm 0.6^{\mathrm{a}}$ & \\
\hline \multicolumn{5}{|c|}{ 12-week time point (prior to interventions) } \\
\hline Body weight (g) & $37.3 \pm 0.7$ & $38.8 \pm 0.9$ & $29.1 \pm 0.3^{\mathrm{a}}$ & $29.6 \pm 0.3^{\mathrm{a}}$ \\
\hline Blood glucose (mmol/l) & $9.1 \pm 0.3$ & $9.1 \pm 0.3$ & $27.5 \pm 0.5^{\mathrm{a}}$ & $27.5 \pm 1.0^{\mathrm{a}}$ \\
\hline \multicolumn{5}{|c|}{ 19-week time point (final measurements) } \\
\hline Body weight (g) & $39.2 \pm 0.8$ & $39.6 \pm 1.0$ & $29.1 \pm 0.4^{\mathrm{a}}$ & $29.1 \pm 0.3^{\mathrm{a}}$ \\
\hline Blood glucose (mmol/l) & $9.0 \pm 0.1$ & $9.0 \pm 0.2$ & $27.2 \pm 1.3^{\mathrm{a}}$ & $26.4 \pm 1.7^{\mathrm{a}}$ \\
\hline
\end{tabular}

Data are expressed as mean \pm SEM, $n=18-20$ per group. ${ }^{a} \mathrm{P}<0.01$ vs. the non-diabetic controls.

Table II. Motor and sensory nerve conduction velocities in non-diabetic and diabetic mice maintained with or without PMI-5011 treatment.

\begin{tabular}{lccc}
\hline Variables & Control & $\begin{array}{c}\text { Control with } \\
\text { PMI-5011 }\end{array}$ & $\begin{array}{c}\text { Diabetic with } \\
\text { PMI-5011 }\end{array}$ \\
\hline Baseline (before induction of STZ-diabetes) & & & \\
MNCV (m/sec) & $54.5 \pm 1.1$ & & $43.8 \pm 2.1^{\mathrm{a}}$ \\
SNCV (m/sec) & $39.4 \pm 0.6$ & $32.8 \pm 1.1^{\mathrm{a}}$ \\
12-week time point (prior to interventions) & & & \\
MNCV (m/sec) & $54.9 \pm 1.8$ & & $45.9 \pm 1.6^{\mathrm{a}}$ \\
SNCV (m/sec) & $40.9 \pm 0.7$ & & $32.3 \pm 1.2^{\mathrm{a}}$ \\
19-week time point (final measurements) & $53.6 \pm 1.6$ & $54.6 \pm 1.3$ & $32.9 \pm 1.7^{\mathrm{b}}$ \\
MNCV (m/sec) & $40.0 \pm 0.5$ & $39.3 \pm 0.5$ & $37.4 \pm 1.1^{\mathrm{b}}$ \\
SNCV (m/sec) & & & 3.5 \\
\hline
\end{tabular}

Data are expressed as mean $\pm \mathrm{SEM}, \mathrm{n}=8-9$ per group. $\mathrm{MNCV}$, motor nerve conduction velocity; SNCV, sensory nerve conduction velocity; ${ }^{\mathrm{a}} \mathrm{P}<0.01$ vs. the non-diabetic controls; ${ }^{\mathrm{b}} \mathrm{P}<0.01$ vs. the untreated diabetic group. 
Table III. Indices of small sensory nerve fiber function in non-diabetic and diabetic mice maintained with or without PMI-5011 treatment.

\begin{tabular}{|c|c|c|c|c|}
\hline Variables & Control & $\begin{array}{l}\text { Control with } \\
\text { PMI-5011 }\end{array}$ & Diabetic & $\begin{array}{l}\text { Diabetic with } \\
\text { PMI-5011 }\end{array}$ \\
\hline \multicolumn{5}{|c|}{ Baseline (before induction of STZ-diabetes) } \\
\hline Paw withdrawal latency (sec) & $8.9 \pm 0.3$ & & & \\
\hline Tail-flick response latency (sec) & $2.62 \pm 0.05$ & & & \\
\hline Mechanical withdrawal threshold (g) & $121 \pm 3.0$ & & & \\
\hline Tactile response threshold $(\mathrm{g})$ & $2.02 \pm 0.11$ & & & \\
\hline \multicolumn{5}{|l|}{ 12-week time point (prior to interventions) } \\
\hline Paw withdrawal latency (sec) & $9.3 \pm 0.3$ & & $16.9 \pm 1.0^{\mathrm{a}}$ & \\
\hline Tail-flick response latency (sec) & $2.7 \pm 0.1$ & & $4.5 \pm 0.3^{\mathrm{a}}$ & \\
\hline Mechanical withdrawal threshold (g) & $116.3 \pm 1.5$ & & $145.6 \pm 4.1^{\mathrm{a}}$ & \\
\hline Tactile response threshold $(\mathrm{g})$ & $1.9 \pm 0.2$ & & $0.9 \pm 0.1^{\mathrm{a}}$ & \\
\hline \multicolumn{5}{|l|}{ 19-week time point (final measurements) } \\
\hline Paw withdrawal latency (sec) & $10 \pm 0.5$ & $9.1 \pm 0.4$ & $15.6 \pm 1.1^{\mathrm{a}}$ & $12.8 \pm 0.7^{\mathrm{a}, \mathrm{c}}$ \\
\hline Tail-flick response latency $(\mathrm{sec})$ & $2.5 \pm 0.1$ & $2.5 \pm 0.1$ & $4.8 \pm 0.3^{\mathrm{a}}$ & $3.2 \pm 0.2^{\mathrm{a}, \mathrm{c}}$ \\
\hline Mechanical withdrawal threshold (g) & $107.3 \pm 3.3$ & $108.1 \pm 2.3$ & $144.8 \pm 5.4^{\mathrm{a}}$ & $119.3 \pm 2.5^{\mathrm{a}, \mathrm{c}}$ \\
\hline Tactile response threshold $(\mathrm{g})$ & $1.7 \pm 0.2$ & $1.6 \pm 0.1$ & $0.8 \pm 0.1^{\mathrm{a}}$ & $1.1 \pm 0.04^{\mathrm{a}, \mathrm{b}}$ \\
\hline
\end{tabular}

Data are expressed as mean $\pm \mathrm{SEM}, \mathrm{n}=7-10$ per group. ${ }^{\mathrm{a}} \mathrm{P}<0.01$ vs. the non-diabetic controls; ${ }^{\mathrm{b}} \mathrm{P}<0.05$ and ${ }^{\mathrm{c}} \mathrm{P}<0.01$ vs. the untreated diabetic group.

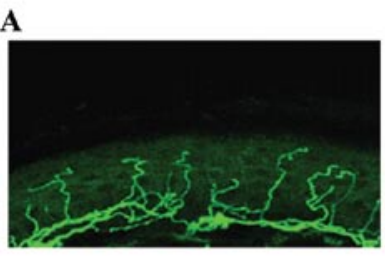

C

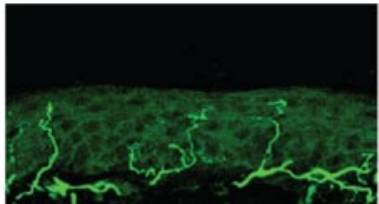

D

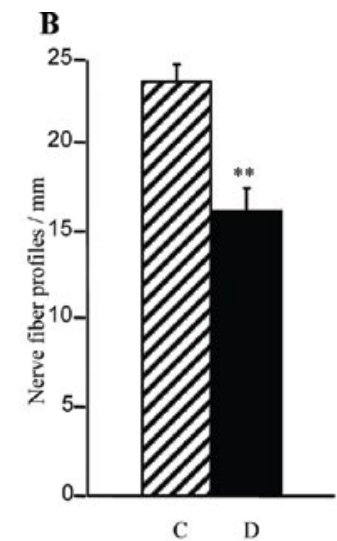

C

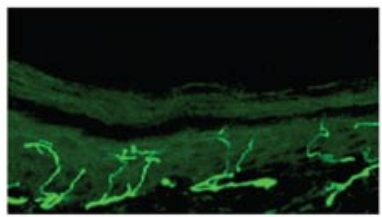

C
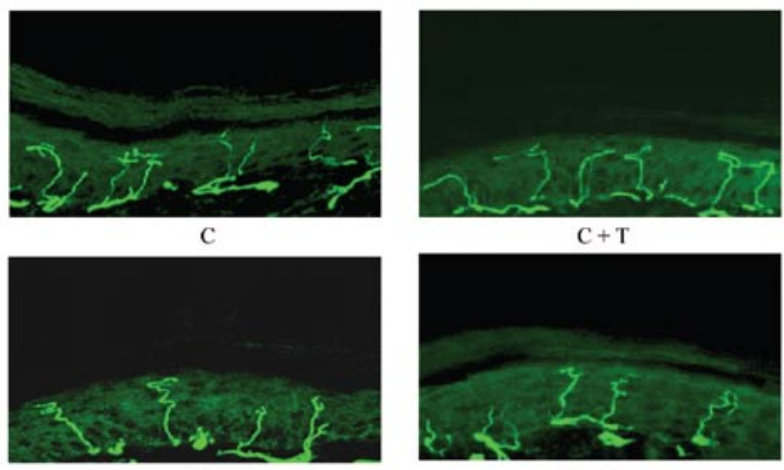

D

$\mathrm{C}+\mathrm{T}$

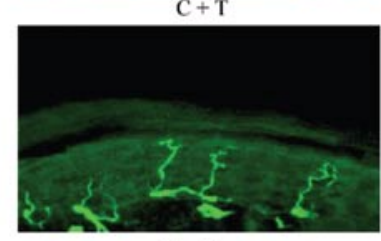

$\mathrm{D}+\mathrm{T}$

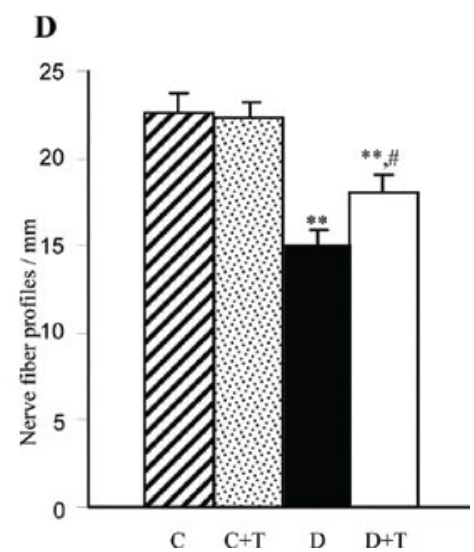

C $\quad \mathrm{C}+\mathrm{T} \quad \mathrm{D} \quad \mathrm{D}+\mathrm{T}$

Figure 1. Intra-epidermal nerve fiber profiles in (A) and (B) control and diabetic mice at the 12-week time point prior to PMI-5011 intervention, and in (C) and (D) control and diabetic mice maintained with or without PMI-5011 treatments (19-week time point). (A) and (C) Representative images of intraepidermal nerve fiber profiles, magnification x40; (B) and (D). Skin fiber density. Mean \pm SEM, n=9-13 per group; C, control mice; D, diabetic mice; T, PMI-5011 treatment; ${ }^{* *} \mathrm{P}<0.01$ vs. the non-diabetic control group; ${ }^{*} \mathrm{P}<0.05$ vs. the diabetic mice treated with $\mathrm{PMI}-5011$. 

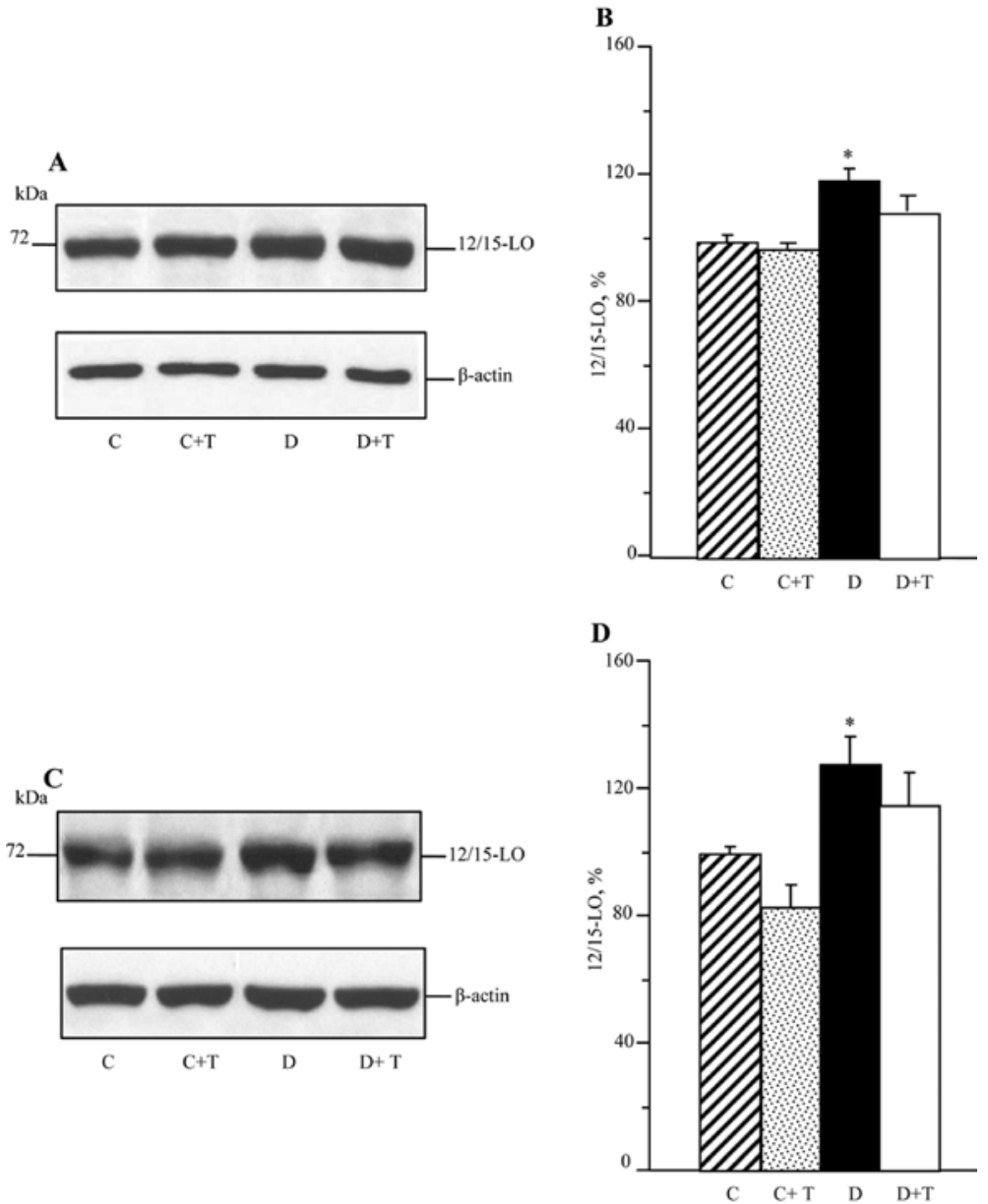

Figure 2. Representative Western blot analyses of 12/15-lipoxygenase expression (A) and (C) and 12/15-lipoxygenase protein contents (\%) assessed by densitometry (B) and (D), in the sciatic nerve and spinal cord of control and diabetic mice maintained with or without PMI-5011 treatments. C, control; D, diabetic; T, PMI-5011 treatment; 12/15 LO, 12/15-lipoxygenase. Mean \pm SEM, $n=7-8$ per group. " $\mathrm{P}<0.05$ vs. the non-diabetic control group.

essentially normalized MNCV and SNCV in diabetic mice, without affecting those variables in the non-diabetic group.

The sensitivities to noxious thermal, mechanical, and tactile stimuli were similar in non-diabetic mice at the beginning of the study and at the 12-week and 19-week time points (Table III). Diabetic mice displayed thermal hypoalgesia (both in Hargreaves paw withdrawal and tail-flick tests) as well as mechanical hypoalgesia and tactile allodynia at both the 12-week and 19-week time points after induction of diabetes. PMI-5011 treatment partially corrected all three sensory disorders in diabetic mice, without affecting thermal response latencies or mechanical and tactile response thresholds in the non-diabetic controls.

Diabetic mice manifested a $31 \%$ reduction in INFD at the 12-week time point (Fig. 1A and B). This reduction progressed to $34 \%$ at the 19 -week time point (Fig. 1C and D). PMI-5011 treatment did not affect INFD in non-diabetic mice, but slowed down intra-epidermal nerve fiber degeneration and induced their regeneration in diabetic mice. INFD in the PMI-treated diabetic mice group was $20 \%$ lower than in the non-diabetic control group, and $20 \%$ higher than in the untreated diabetic group.

As reported previously (34), C57Bl6/J mice with a 12-week duration of diabetes display an 12/15-LO overexpression and activation as well as oxidative-nitrosative stress in the sciatic
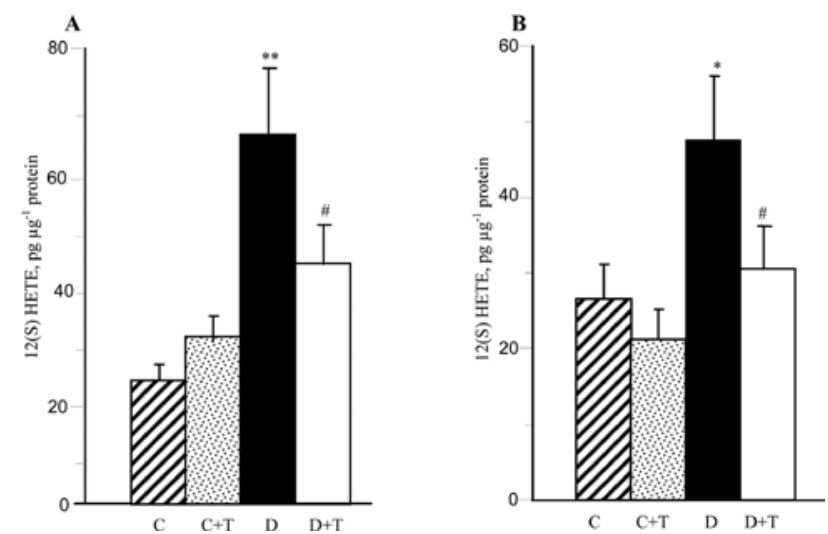

Figure 3. 12(S) hydroxyeicosatetraenoic acid concentrations in the sciatic nerve (A) and spinal cord (B) of control and diabetic mice maintained with or without PMI-5011 treatments. C, control; D, diabetic; T, PMI-5011 treatment; 12(S)HETE, 12(S) hydroxyeicosatetraenoic acid. Mean \pm SEM, n=7-9 per group. ${ }^{*} \mathrm{P}<0.05$ and ${ }^{* *} \mathrm{P}<0.01$ vs. the non-diabetic control group. ${ }^{\text {}} \mathrm{P}<0.05$ vs. the untreated diabetic group.

nerve and spinal cord. They also exhibit glucose and sorbitol pathway intermediate accumulation in both tissue targets for DPN (not shown). In the present study, increased 12/15-LO expression (Fig. 2) and 12(S)HETE concentrations (Fig. 3) 

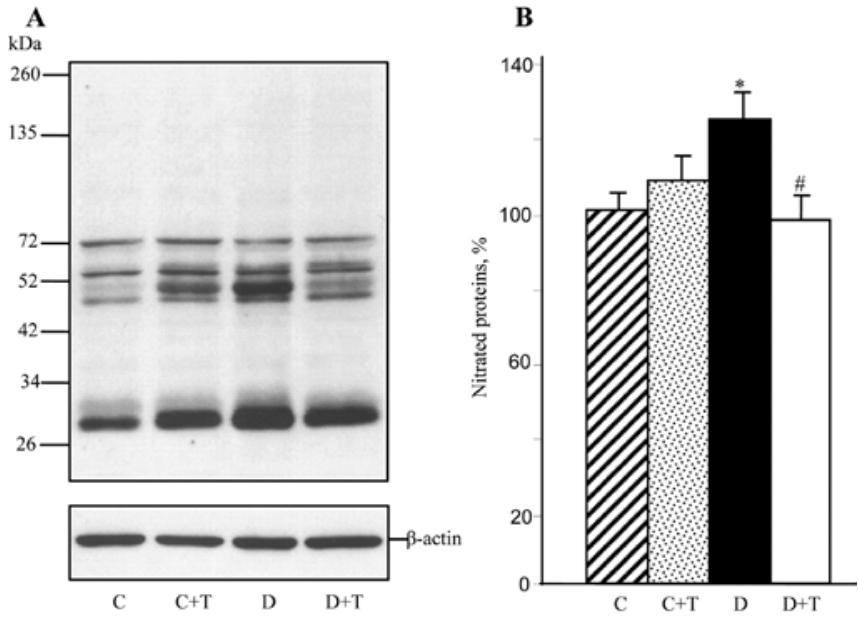$$
\text { C }
$$

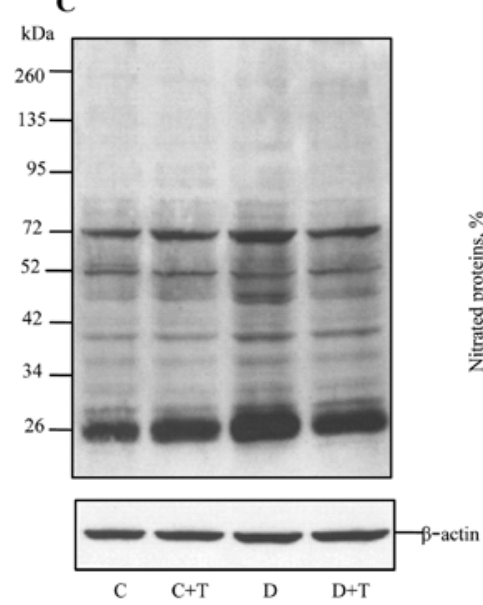

D

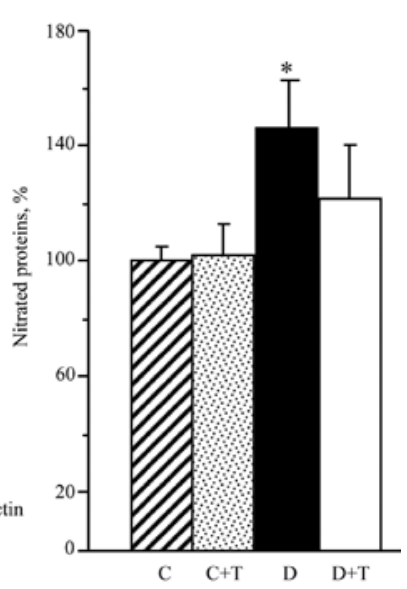

Figure 4. Representative Western blot analyses of nitrated proteins (A) and (C) and nitrated protein contents (\%) assessed by densitometry (B) and (D) in the sciatic nerve and spinal cord of control and diabetic mice maintained with or without PMI-5011 treatments. C, control; D, diabetic; T, PMI-5011 treatment. Mean \pm SEM, $n=6-8$ per group. ${ }^{*} \mathrm{P}<0.05$ vs. the non-diabetic control group. ${ }^{~} \mathrm{P}<0.05$ vs. the untreated diabetic group.

were found in the sciatic nerve and spinal cord of untreated mice with a 19-week duration of diabetes. PMI-5011 treatment did not affect diabetes-induced 12/15-LO overexpression, but reduced 12(S)HETE concentrations, indicative of a reduction in 12/15-LO activity, in both tissues.

In addition, mice with STZ-diabetes of a 19-week duration displayed oxidative-nitrosative stress in the peripheral nervous system (Fig. 4). Nitrated protein levels were increased by 25 and $46 \%$ in the sciatic nerve and spinal cord, respectively. PMI-5011 treatment completely blunted diabetes-associated nitrated protein accumulation in the sciatic nerve, and tended to reduce this variable in the spinal cord although the difference with the untreated diabetic group was not statistically significant $(\mathrm{P}=0.21)$.

Sciatic nerve glucose, sorbitol, and fructose concentrations were elevated 8.8 -fold, 1.9-fold, and 3-fold, respectively, in the group of mice with STZ-diabetes of a 19-week duration compared to the non-diabetic control group. Treatment with PMI-5011 did not affect the sciatic nerve glucose or sorbitol pathway intermediate concentrations in either non-diabetic or diabetic mice (Fig. 5).
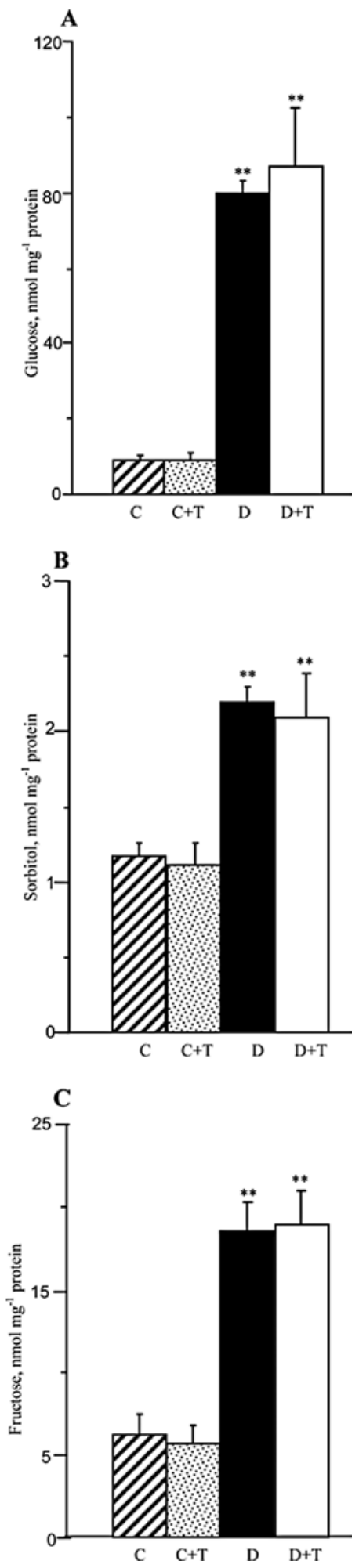

Figure 5. Glucose (A), sorbitol (B), and fructose (C) concentrations in the sciatic nerve and spinal cord of control and diabetic mice maintained with or without PMI-5011 treatments. C, control; D, diabetic; T, PMI-5011 treatment. Mean \pm SEM, $n=5-9$ per group. ${ }^{* *} \mathrm{P}<0.01$ vs. the non-diabetic control group.

\section{Discussion}

The present study provides evidence of the therapeutic efficacy of PMI-5011, an ethanolic extract of Artemisia dracunculus L. against MNCV and SNCV deficits, thermal and mechanical 
hypoalgesia, and tactile allodynia in STZ-diabetic mice, a model of Type I DPN. Furthermore, PMI-5011 treatment slowed down diabetes-associated intra-epidermal nerve fiber loss and induced nerve fiber regeneration, although a complete restoration of normal INFD was not achieved.

The DCCT/EDIC (Diabetes Control and Complications Trial/Epidemiology of Diabetes Interventions and Complications) Study (35) and the United Kingdom Prospective Diabetes Study (36) identified hyperglycemia as a leading contributing factor in the pathogenesis of DPN associated with Type I (insulin-dependent) and Type II (non-insulin-dependent) diabetes, respectively. It has previously been reported that PMI-5011 treatment lowers diabetic hyperglycemia in both Type I STZ-diabetic and Type II diabetic KK-A $(\gamma)$ mice (8). Whereas a small reduction of non-fasting blood glucose concentrations was noticed in the PMI-5011-treated HFD-fed mice in our previous experiments (13), no hypoglycemic effect of the extract was observed in the current study in STZ-diabetic mice which displayed severe $(>25 \mathrm{mmol} / \mathrm{l})$ hyperglycemia. In line with these data, PMI-5011 did not have any effect on diabetes-associated sciatic nerve glucose accumulation. Thus, the efficacy of PMI-5011 against functional and morphological manifestations of DPN is not due to the alleviation of diabetic hyperglycemia or to the decrease in glucose availability in tissue-sites for DPN.

It has also been reported that, similarly to other flavonoids (37), the PMI-5011 components 4,5-di-O-caffeoylquinic acid, 6-demethoxycapillarisin, and 2',4'-dihydroxy-4-methoxydihydrochalcone, as well as the total extract, displayed significant aldose reductase inhibiting properties (12). However, no effect of PMI-5011 on the sciatic nerve sorbitol pathway activity in either non-diabetic or diabetic mice was observed in the present study. The lack of efficacy is unlikely due to the limited entry of PMI-5011 into the peripheral nerve, because other biochemical variables such as 12(S)HETE and nitrated protein levels were significantly different between untreated and PMI-5011-treated diabetic mice.

Taking into consideration that both oxidative-nitrosative stress $(21,23-25)$ and 12/15-LO up-regulation $(34,38)$ are involved in the diabetes-induced nerve conduction slowing, the alleviation of MNCV and SNCV deficits in PMI-5011-treated diabetic mice could at least partially be related to the inhibition of both phenomena in the peripheral nerve and spinal cord. Also note, that whereas a reduction in 12(S)HETE and nitrated protein accumulation with PMI-5011 treatment was detected in the whole peripheral nerve, it is quite plausible that PMI-5011 inhibits 12/15-LO up-regulation and oxidative-nitrosative stress in vasa nervorum. Endothelial cells contain 12/15-LO, accumulate 12(S)HETE, and display oxidative-nitrosative stress in response to high glucose $(39,40)$. Increased superoxide and peroxynitrite accumulation have been identified in vasa nervorum of STZ-diabetic rats $(31,41,42)$. Both oxidativenitrosative stress $(21,23,25,41,42)$ and increased $12 / 15$-LO activity $(39,40)$ contribute to endothelial dysfunction, an important factor in MNCV and SNCV deficits associated with DPN $(16,18,21,23,25,31,33,41,43,44)$.

Evidence for the involvement of oxidative-nitrosative stress $(21,24,31,45)$ and of the $12 / 15$-LO up-regulation $(34,38)$ in diabetes-induced small sensory nerve fiber dysfunction and neuropathic pain is emerging. The SYDNEY 2 (6) trial identified a beneficial effect of the antioxidant $\alpha$-lipoic acid on symptomatic diabetic polyneuropathy, and, in particular, stabbing and burning pain. Thus it is plausible, that the beneficial effects of PMI-5011 on diabetes-associated thermal and mechanical hypoalgesia and tactile allodynia are also mediated through the inhibition of oxidative-nitrosative stress and activation of 12/15-LO, although no experimental tools for quantitative characterization of these two phenomena in small nerve fibers are currently available.

In our previous study, the 12/15-LO inhibitor cinnamyl-3,4dihydroxy- $\alpha$-cyanocinnamate alleviated oxidative-nitrosative stress in the sciatic nerve and spinal cord of STZ-diabetic mice (34). Furthermore, we observed a similar effect of 12/15-LO gene deficiency in the HFD-fed mouse model (34). Thus, it is plausible that the antioxidant effect of PMI-5011 is secondary to $12 / 15-\mathrm{LO}$ inhibition. Interestingly, however, in contrast to PMI-5011, 12/15-LO inhibition (34) or gene deficiency (38) did not counteract diabetes-associated loss of intra-epidermal nerve fibers. Thus, the increase of INFD in PMI-5011-treated diabetic mice is likely to be mediated through mechanisms other than inhibition of 12/15-LO activity or oxidative-nitrosative stress.

In conclusion, PMI-5011, the ethanolic extract of Artemisia dracunculus L., alleviates nerve conduction slowing and small sensory nerve fiber dysfunction, and promotes small sensory nerve fiber regeneration in experimental Type I DPN. Its mechanisms of action are likely to include, but are not limited to, the inhibition of oxidative-nitrosative stress and 12/15-LO activation. PMI-5011, a safe and non-toxic product, may find use in the management of DPN and of related complications (impaired wound healing) in human subjects with diabetes mellitus. Evaluation of the effects of PMI-5011 on other diabetic complications (cardiovascular disease, nephropathy, retinopathy) that develop with participation of the 12/15-LO up-regulation and/or of oxidative-nitrosative stress is warranted.

\section{Acknowledgements}

The study was supported by the American Diabetes Association Research Grant 7-05-RA-102 (I.G.O.), the National Institutes of Health Grants DK074517, DK077141, and DK074517 (all to I.G.O.), and the Intramural Research Program of the National Institutes of Health/National Institute of Alcohol Abuse and Alcoholism (to P.P.). Dr Pierre Watcho, University of Dschang, Cameroon, was a recipient of a fellowship grant from the Agence Universitaire de la Francophonie (AUF). The preparation of PMI-5011 kindly provided by Dr Ilya Raskin and Dr David Ribnicky, was supported by the National Institutes of Health Grant NCCAM/OD P50AT002776 to the Botanical Research Center at the Pennington Biomedical Research Center and The Biotech Center of Rutgers University. The Cell Biology and Bioimaging Core utilized in this work is supported in part by COBRE (NIH P20 RR021945) and CNRU (NIH 1P30-DK072476) center grants from the National Institutes of Health. The authors thank Dr Douglas E. Wright from the University of Kansas Medical Center, (Kansas City, KS, USA) and Dr Gary L. Pittenger from Eastern Virginia Medical School (Norfolk, VA, USA), for valuable recommendations regarding intra-epidermal nerve fiber density measurements. 


\section{References}

1. Boulton AJ, Vinik AI, Arezzo JC, Bril V, Feldman EL, Freeman R, Malik RA, Maser RE, Sosenko JM and Ziegler D: American Diabetes Association: Diabetic neuropathies: a statement by the American Diabetes Association. Diabetes Care 28: 956-962, 2005.

2. Tesfaye S, Boulton AJ, Dyck PJ, Freeman R, Horowitz M, Kempler P, Lauria G, Malik RA, Spallone V, Vinik A, Bernardi L and Valensi P: Toronto Diabetic Neuropathy Expert Group: Diabetic neuropathies: update on definitions, diagnostic criteria, estimation of severity, and treatments. Diabetes Care 33: 2285-2293, 2010

3. Calcutt NA: Experimental models of painful diabetic neuropathy. J Neurol Sci 220: 137-139, 2004.

4. Veves A, Backonja M and Malik RA: Painful diabetic neuropathy: epidemiology, natural history, early diagnosis, and treatment options. Pain Med 9: 660-674, 2008

5. Hotta N, Akanuma Y, Kawamori R, Matsuoka K, Oka Y, Shichiri M, Toyota T, Nakashima M, Yoshimura I, Sakamoto N and Shigeta Y: Long-term clinical effects of epalrestat, an aldose reductase inhibitor, on diabetic peripheral neuropathy: the 3-year multicenter, comparative Aldose Reductase Inhibitor-Diabetes Complications Trial. Diabetes Care 29: 1538-1544, 2006.

6. Ziegler D, Ametov A, Barinov A, Dyck PJ, Gurieva I, Low PA, Munzel U, Yakhno N, Raz I, Novosadova M, Maus J and Samigullin R: Oral treatment with alpha-lipoic acid improves symptomatic diabetic polyneuropathy: the SYDNEY 2 trial. Diabetes Care 29: 2365-2370, 2006.

7. Ribnicky DM, Poulev A, O'Neal J, Wnorowski G, Malek DE, Jäger R and Raskin I: Toxicological evaluation of the ethanolic extract of Artemisia dracunculus L. for use as a dietary supplement and in functional foods. Food Chem Toxicol 42: 585-598, 2004

8. Ribnicky DM, Poulev A, Watford M, Cefalu WT and Raskin I: Antihyperglycemic activity of Tarralin, an ethanolic extract of Artemisia dracunculus L. Phytomedicine 13: 550-557, 2006.

9. Govorko D, Logendra S, Wang Y, Esposito D, Komarnytsky S, Ribnicky D, Poulev A, Wang Z, Cefalu WT and Raskin I: Polyphenolic compounds from Artemisia dracunculus L. inhibit PEPCK gene expression and gluconeogenesis in an H4IIE hepatoma cell line. Am J Physiol Endocrinol Metab 293: 1503-1510, 2007

10. Wang ZQ, Ribnicky D, Zhang XH, Raskin I, Yu Y and Cefalu WT: Bioactives of Artemisia dracunculus $\mathrm{L}$ enhance cellular insulin signaling in primary human skeletal muscle culture. Metabolism 57: 58-64, 2008.

11. Wang ZQ, Ribnicky D, Zhang XH, Zuberi A, Raskin I, Yu Y and Cefalu WT: An extract of Artemisia dracunculus L. enhances insulin receptor signaling and modulates gene expression in skeletal muscle in KK-A(y) mice. J Nutr Biochem: May 4, 2010 (Epub ahead of print).

12. Logendra S, Ribnicky DM, Yang H, Poulev A, Ma J, Kennelly EJ, and Raskin I: Bioassay-guided isolation of aldose reductase inhibitors from Artemisia dracunculus. Phytochemistry 67: 1539-1546, 2006.

13. Watcho P, Stavniichuk R, Ribnicky DM, Raskin I and Obrosova IG: High-fat diet-induced neuropathy of prediabetes and obesity: effect of PMI-5011, an ethanolic extract of Artemisia dracunculus L. Mediators Inflamm 2010: 268547, 2010.

14. Kheterpal I, Coleman L, Ku G, Wang ZQ, Ribnicky D and Cefalu WT: Regulation of insulin action by an extract of Artemisia dracunculus L. in primary human skeletal muscle culture: a proteomics approach. Phytother Res 24: 1278-1284, 2010.

15. Francis G, Martinez J, Liu W, Nguyen T, Ayer A, Fine J, Zochodne D, Hanson LR, Frey WH II and Toth C: Intranasal insulin ameliorates experimental diabetic neuropathy. Diabetes 58: 934-945, 2009

16. Cameron NE, Cotter MA, Basso M and Hohman TC: Comparison of the effects of inhibitors of aldose reductase and sorbitol dehydrogenase on neurovascular function, nerve conduction and tissue polyol pathway metabolites in streptozotocin-diabetic rats. Diabetologia 40: 271-281, 1997.

17. Ho EC, Lam KS, Chen YS, Yip JC, Arvindakshan M, Yamagishi S, Yagihashi S, Oates PJ, Ellery CA, Chung SS and Chung SK: Aldose reductase-deficient mice are protected from delayed motor nerve conduction velocity, increased c-Jun NH2-terminal kinase activation, depletion of reduced glutathione, increased superoxide accumulation, and DNA damage. Diabetes 55: 1946-1953, 2006.
18. Nakamura J, Kato K, Hamada Y, Nakayama M, Chaya S, Nakashima E, Naruse K, Kasuya Y, Mizubayashi R, Miwa K, Yasuda Y, Kamiya H, Ienaga K, Sakakibara F, Koh N and Hotta N: A protein kinase C-beta-selective inhibitor ameliorates neural dysfunction in streptozotocin-induced diabetic rats. Diabetes 48: 2090-2095, 1999.

19. Obrosova IG, Van Huysen C, Fathallah L, Cao XC, Greene DA and Stevens MJ: An aldose reductase inhibitor reverses early diabetesinduced changes in peripheral nerve function, metabolism, and antioxidative defense. FASEB J 16: 123-125, 2002.

20. Yagihashi S, Yamagishi SI, Wada Ri R, Baba M, Hohman TC, Yabe-Nishimura $C$ and Kokai Y: Neuropathy in diabetic mice overexpressing human aldose reductase and effects of aldose reductase inhibitor. Brain 124: 2448-2458, 2001

21. Cameron NE, Tuck Z, McCabe L and Cotter MA: Effect of the hydroxyl radical scavenger, dimethylthiourea, on peripheral nerve tissue perfusion, conduction velocity and nociception in experimental diabetes. Diabetologia 44: 1161-1169, 2001.

22. Low PA, Nickander KK and Tritschler HJ: The roles of oxidative stress and antioxidant treatment in experimental diabetic neuropathy. Diabetes 46: 38-42, 1997.

23. Nagamatsu M, Nickander KK, Schmelzer JD, Raya A, Wittrock DA, Tritschler H and Low PA: Lipoic acid improves nerve blood flow, reduces oxidative stress, and improves distal nerve conduction in experimental diabetic neuropathy. Diabetes Care 18: 1160-1167, 1995.

24. Obrosova IG, Mabley JG, Zsengellér Z, Charniauskaya T, Abatan OI, Groves JT and Szabó C: Role for nitrosative stress in diabetic neuropathy: evidence from studies with a peroxynitrite decomposition catalyst. FASEB J 19: 401-403, 2005.

25. Stevens MJ, Obrosova I, Cao X, Van Huysen C and Greene DA: Effects of DL-alpha-lipoic acid on peripheral nerve conduction, blood flow, energy metabolism, and oxidative stress in experimental diabetic neuropathy. Diabetes 49: 1006-1015, 2000.

26. Bierhaus A, Haslbeck KM, Humpert PM, Liliensiek B, Dehmer T, Morcos M, Sayed AA, Andrassy M, Schiekofer S, Schneider JG, Schulz JB, Heuss D, Neundörfer B, Dierl S, Huber J, Tritschler H, Schmidt AM, Schwaninger M, Haering HU, Schleicher E, Kasper M, Stern DM, Arnold B and Nawroth PP: Loss of pain perception in diabetes is dependent on a receptor of the immunoglobulin superfamily. J Clin Invest 114: 1741-1751, 2004.

27. Cameron NE and Cotter MA: Pro-inflammatory mechanisms in diabetic neuropathy: focus on the nuclear factor kappa B pathway. Curr Drug Targets 9: 60-67, 2008.

28. Kumar A and Sharma SS: NF-kappaB inhibitory action of resveratrol: a probable mechanism of neuroprotection in experimental diabetic neuropathy. Biochem Biophys Res Commun 394: 360-365, 2010.

29. Wang Y, Schmeichel AM, Iida H, Schmelzer JD and Low PA: Enhanced inflammatory response via activation of NF-kappaB in acute experimental diabetic neuropathy subjected to ischemiareperfusion injury. J Neurol Sci 247: 47-52, 2006.

30. Obrosova IG, Li F, Abatan OI, Forsell MA, Komjáti K, Pacher P, Szabó C and Stevens MJ: Role of poly(ADP-ribose) polymerase activation in diabetic neuropathy. Diabetes 53: 711-720, 2004

31. Obrosova IG, Drel VR, Oltman CL, Mashtalir N, Tibrewala J, Groves JT and Yorek MA: Role of nitrosative stress in early neuropathy and vascular dysfunction in streptozotocin-diabetic rats. Am J Physiol Endocrinol Metab 293: 1645-1655. 2007.

32. Obrosova IG, Xu W, Lyzogubov VV, Ilnytska O, Mashtalir N, Vareniuk I, Pavlov IA, Zhang J, Slusher B and Drel VR: PARP inhibition or gene deficiency counteracts intraepidermal nerve fiber loss and neuropathic pain in advanced diabetic neuropathy. Free Radic Biol Med 44: 972-981, 2008.

33. Obrosova IG, Van Huysen C, Fathallah L, Cao X, Stevens MJ and Greene DA: Evaluation of alpha(1)-adrenoceptor antagonist on diabetes-induced changes in peripheral nerve function, metabolism, and antioxidative defense. FASEB J 14: 1548-1558, 2000.

34. Stavniichuk R, Drel VR, Shevalye H, Vareniuk I, Stevens MJ, Nadler JL and Obrosova IG: Role of 12/15-lipoxygenase in nitrosative stress and peripheral prediabetic and diabetic neuropathies. Free Radic Biol Med 49: 1036-1045, 2010.

35. Albers JW, Herman WH, Pop-Busui R, Feldman EL, Martin CL Cleary PA, Waberski BH and Lachin JM: Diabetes Control and Complications Trial/Epidemiology of Diabetes Interventions and Complications Research Group. Effect of prior intensive insulin treatment during the Diabetes Control and Complications Trial (DCCT) on peripheral neuropathy in type 1 diabetes during the Epidemiology of Diabetes Interventions and Complications (EDIC) Study. Diabetes Care 33: 1090-1096, 2010 
36. Turner RC and Holman RR: Lessons from UK prospective diabetes study. Diabetes Res Clin Pract 28: 151-157, 1995.

37. Varma SD and Kinoshita JH: Inhibition of lens aldose reductase by flavonoids - their possible role in the prevention of diabetic cataracts. Biochem Pharmacol 25: 2505-2513, 1976.

38. Obrosova IG, Stavniichuk R, Drel VR, Shevalye H, Vareniuk I, Nadler JL and Schmidt RE: Different roles of 12/15-lipoxygenase in diabetic large and small fiber peripheral and autonomic neuropathies. Am J Pathol 177: 1436-1447, 2010.

39. Natarajan R and Nadler JL: Lipoxygenases and lipid signaling in vascular cells in diabetes. Front Biosci 8: 783-795, 2003.

40. Natarajan R and Nadler JL: Lipid inflammatory mediators in diabetic vascular disease. Arterioscler Thromb Vasc Biol 24: 1542-1548, 2004.

41. Coppey LJ, Gellett JS, Davidson EP, Dunlap JA, Lund DD and Yorek MA: Effect of antioxidant treatment of streptozotocininduced diabetic rats on endoneurial blood flow, motor nerve conduction velocity, and vascular reactivity of epineurial arterioles of the sciatic nerve. Diabetes 50: 1927-1937, 2001.
42. Coppey LJ, Gellett JS, Davidson EP and Yorek MA: Preventing superoxide formation in epineurial arterioles of the sciatic nerve from diabetic rats restores endothelium-dependent vasodilation. Free Radic Res 37: 33-40, 2003.

43. Coppey LJ, Davidson EP, Rinehart TW, Gellett JS, Oltman CL, Lund DD and Yorek MA: ACE inhibitor or angiotensin II receptor antagonist attenuates diabetic neuropathy in streptozotocin-induced diabetic rats. Diabetes 55: 341-348, 2006.

44. Naruse K, Hamada Y, Nakashima E, Kato K, Mizubayashi R, Kamiya H, Yuzawa Y, Matsuo S, Murohara T, Matsubara T, Oiso Y and Nakamura J: Therapeutic neovascularization using cord blood-derived endothelial progenitor cells for diabetic neuropathy. Diabetes 54: 1823-1828, 2005.

45. Obrosova IG: Diabetic painful and insensate neuropathy: pathogenesis and potential treatments. Neurotherapeutics 6: 638-647, 2009. 